\title{
Predicted distributions and conservation status of two threatened Southeast Asian small carnivores: the banded civet and Hose's civet
}

\begin{abstract}
Knowledge of the distribution and habitat preferences of a species is of paramount importance when assessing its conservation status. We used accurately recorded occurrence records and ecological niche modelling to predict the distribution of two threatened and poorly known small carnivore species that occur in Southeast Asia, the banded civet (Hemigalus derbyanus) and Hose's civet (Diplogale hosei), and analysed their spatial niche differentiation for habitat and elevation. We then identified possible anthropogenic threats, and used our modelling predictions to recommend surveying priorities. The predicted distribution of the banded civet was principally in lowland evergreen forest in southern Myanmar/Thailand, Peninsular Malaysia, Sumatra, Borneo and three Mentawai Islands (Siberut, Sipora and South Pagai), and for Hose's civet in evergreen forest across the higher elevation regions of Borneo. Our niche analyses suggested that there is a tendency for these two species to separate spatially along an elevation gradient: the banded civet is mainly found in lowland areas, whereas Hose's civet primarily occurs at higher elevations. Our study strongly indicated that these two viverrids are forest-dependent species that may be threatened by forest loss, degradation and fragmentation. Field surveys should be prioritised in areas where each species is predicted to occur and no records currently exist.
\end{abstract}

Keywords: Diplogale hosei; ecological niche; Hemigalus derbyanus; Maxent; Viverridae.

\footnotetext{
*Corresponding author: Andrew P. Jennings, UMR MNHN CNRS 7205, Département Systématique et Evolution, Muséum National d'Histoire Naturelle, CP 51, 57 rue Cuvier, 75231 Paris Cedex 05, France, e-mail: smallcarnivores@yahoo.com John Mathai: Institute of Biodiversity and Environmental Conservation, Universiti Malaysia Sarawak, 94300 Kota Samarahan, Sarawak, Malaysia

Jedediah Brodie: Departments of Zoology and Botany, University of British Columbia, Vancouver, BC, Canada

Anthony J. Giordano: Department of Natural Resource Management, Box 42125, Goddard Hall, Texas Tech University, Lubbock, TX 79409 , USA

Geraldine Veron: UMR MNHN CNRS 7205, Département Systématique et Evolution, Muséum National d'Histoire Naturelle, CP 51, 57 rue Cuvier, 75231 Paris Cedex 05, France
}

\section{Introduction}

Knowledge of geographical distributions and habitat preferences is central to the conservation of threatened species and is of paramount importance when assessing their conservation status and evaluating levels of threats and protection (Thorn et al. 2009, Jackson and Robertson 2011, Rondinini et al. 2011). Presence-only ecological niche modelling (ENM) can be a useful tool for predicting the distributions of poorly known species in remote and inaccessible regions (Gaubert et al. 2006, Papes and Gaubert 2007, Wilting et al. 2010, Jennings and Veron 2011, Jenks et al. 2012). The outputs of ENM can aid conservation planning by highlighting potential unknown populations and key areas for fieldwork and conservation initiatives (Peterson 2006, Thorn et al. 2009, Jackson and Robertson 2011). ENM uses the environmental characteristics of known distribution points to assess the suitability of regions where currently no records of a species exist (Elith et al. 2006). Though presence-only models may potentially generate biased predictions (Phillips et al. 2009), Gormley et al. (2011) have shown that these methods can generate very similar predicted distributions to those that use occupancy modelling and observed presence-absence data.

Although the lack of species records from regions of predicted presence can be simply an artefact of inadequate sampling effort, unoccupied areas might highlight instances where other factors, such as biogeographical and ecological barriers or interspecific competition, have played a role in restricting the range of a species (Phillips et al. 2006, Jennings and Veron 2011). Species persistence in predicted areas may also be influenced by humaninduced factors, such as habitat loss and hunting (Corlett 2007, Thorn et al. 2009). Thus, identifying and assessing the level of anthropogenic threats is vital for developing conservation strategies.

The banded civet Hemigalus derbyanus (Gray, 1837) and Hose's civet Diplogale hosei (Thomas, 1892) are two closely related small carnivore species within the subfamily Hemigalinae, Viverridae (Veron 2010, Wilting and Fickel 2012) that occur within Southeast Asia (Jennings and Veron 2009). Both species have long slender bodies 